\title{
A novel approach to monitoring of the diffusion junction potential in speciation studies by polarography under very acidic conditions. Part II: The quasi-reversible $\mathrm{Cu}$ (II)-picolinic acid system.
}

\author{
Caren Billing, ${ }^{\mathrm{a}} *$ Ignacy Cukrowski ${ }^{\mathrm{b}}$ \\ a Molecular Sciences Institute, School of Chemistry, University of the Witwatersrand, P.O. Wits, Johannesburg, 2050, South \\ Africa \\ b Department of Chemistry, University of Pretoria, Pretoria, 0002, South Africa \\ * e-mail: caren.billing@ wits.ac.za
}

\begin{abstract}
The use of polarography to accurately determine stability constants of complexes formed under very acidic conditions (below pH 2) is demonstrated. The diffusion junction potentials, which must be accounted for below pH 2, were evaluated by applying protocols developed where $\mathrm{Tl}(\mathrm{I})$ is used as an internal reference. The $\mathrm{Cu}$ (II)-picolinic acid (2pyridinecarboxylic acid) system studied was chosen since the $\mathrm{CuL}^{+}$species only exists in solution below $\mathrm{pH} 2$ under the conditions used and literature data exists to confirm the accuracy of procedure. Additionally, the reduction of $\mathrm{Cu}$ (II) was quasi-reversible and procedures to determine the reversible half-wave potentials were investigated. Average log $\beta$ values of $7.75 \pm 0.09$ for $\mathrm{CuL}^{+}$and $14.8 \pm 0.1$ for $\mathrm{CuL}_{2}$ were obtained, which compared well to literature data.
\end{abstract}

Keywords: Acidic conditions, diffusion junction potential, picolinic acid, quasi-reversible, stability constants.

\section{Introduction}

Determining stability constants of metal-ligand complexes under acidic conditions is not trivial. Any technique that employs a reference electrode (RE) has limited accuracy in determining formation constants for species formed below about $\mathrm{pH} 2$. This is due to the large and $\mathrm{pH}$-dependent diffusion junction potential $\left(E_{\mathrm{j}}\right)$ that is formed between the RE filling solution and the sample solution. Glass electrode potentiometry (GEP) has even further limitations under very acidic conditions because mass-balance equations, which are solved for the free hydrogen ion concentration from the deprotonation of the ligand caused by the complexation reaction, cannot be accurately solved when the background solution contains more than about $10^{-2} \mathrm{M}$ strong acid. [1,2] Additionally, irrespective of the technique that is used, the $\mathrm{pH}$ of the solution has to be measured and the $E_{\mathrm{j}}$ constrains the accuracy with which this can be done.

When a metal ion is characterized by high affinity to a ligand then complexation can start at extremely low $\mathrm{pH}$ and the copper(II)-picolinic acid $(\mathrm{Cu}-\mathrm{L})$ system is one among many such examples. Knowledge of chelating properties (which incorporates a metal-ligand model and formation constants of all identified metal species formed) is of importance in many fields [1], hence there were numerous attempts to model the $\mathrm{Cu}-\mathrm{L}$ system [310] using a range of analytical techniques, as shown in Table 1. When using spectrophotometry [3-5], calorimetry [6] or a copper amalgam electrode [7], stability constants for $\mathrm{CuL}$ and $\mathrm{CuL}_{2}$ were determined. However, a large spread in the reported data is observed exemplifying difficulty in studying metal complexes under highly acidic conditions. It is known that GEP is unparalleled in the determination of formation constants and this technique alone provided the majority of all known data in the field of metal ion complexation. [1] As can be seen in Table 1, however, stability constant only for $\mathrm{CuL}_{2}$, which could be investigated only above $\mathrm{pH} \sim 2$, was determined by GEP [8] which clearly illustrates intrinsic limitation of this technique as also reported by Suzuki et al. [3] who observed irreproducible 
results generated from GEP. Furthermore, data for CuL, which is fully formed already in highly acidic medium, were not reported from voltammetry [5,6].

The $\mathrm{CuL}$ complex was found and formation constant determined in buffered sample solutions from ligand titrations employing a copper amalgam electrode [7]. This approach minimized errors coming from the junction potential at the reference electrode and we also explored the ligand titration method in this work but without the use of buffers. We avoid employing buffers because (i) our aim is to develop a general-purpose methodology which could also be suitable for highly acidic metal ions, such as bismuth(III), which can only be studied by acid-base titrations [11] and (ii) certain metal ions, and $\mathrm{Cu}(\mathrm{II})$ in particular, might be complexed by buffers; it has been reported that $\mathrm{Cu}$ (II) forms strong complexes even with monoprotonated ligands which are commonly used in preparing buffers for biological applications. [12]

Table 1. Literature formation constants for the copper(II)picolinic acid system at the given ionic strength $(\mu)$ and temperatures.

\begin{tabular}{lllllll}
\hline $\log \boldsymbol{K}_{\mathbf{1}}$ & $\log \boldsymbol{K}_{\mathbf{2}}$ & $\log \boldsymbol{\beta}_{\mathbf{2}}$ & $\mathbf{T} /{ }^{\circ} \mathbf{C}$ & $\boldsymbol{\mu} / \mathbf{M}$ & Technique & Ref \\
\hline 8.6 & 7.4 & 16.0 & 25 & 0.1 & Spec & {$[3]$} \\
8.73 & 6.78 & 15.51 & 25 & 1 & Spec & {$[4]$} \\
7.9 & 6.6 & 14.5 & 20 & 0.2 & Spec & {$[5]$} \\
7.71 & 6.83 & 14.54 & 25 & 1 & Cal & {$[6]$} \\
7.95 & 7.00 & 14.95 & 20 & 0.1 & Cu-Hg & {$[7]$} \\
& 6.0 & & 25 & 0.02 & GEP & {$[8]$} \\
& & 14.88 & 20 & 0.2 & Voltam & {$[5]$} \\
& & 15.35 & 20 & 0.5 & Voltam & {$[9]$} \\
& & 16.1 & 25 & 0.2 & Voltam & {$[10]$} \\
\hline
\end{tabular}

Spec = Spectrophotometry; $\mathrm{Cal}=$ Calorimetry; $\mathrm{Cu}-\mathrm{Hg}=\mathrm{Cu}(\mathrm{II})$ amalgam electrode Voltam $=$ Voltammetry

In previous work, [13] the authors demonstrated that polarography could be used to determine formation constants in solutions at $\mathrm{pH}<2$, provided the diffusion junction potential was compensated for. The variation in $E_{\mathrm{j}}$ values was monitored in-situ as a function of $\mathrm{pH}$ by measuring the reduction potential of thallium(I) which was added to the test solution. It is important to stress that $\mathrm{Tl}(\mathrm{I})$ is not chelated by picolinic acid up to at least $\mathrm{pH} 8$ [13] and its hydrolysis only occurs above $\mathrm{pH} 11$ ( $\log K=0.30$ for $\mathrm{TlOH}$ at $25{ }^{\circ} \mathrm{C}$ and $0.5 \mathrm{M}$ ionic strength [14]). Because of that, any change in the reduction potentials for $\mathrm{Tl}(\mathrm{I})$ below $\mathrm{pH} \sim 2$ could be attributed to changes in $E_{\mathrm{j}}$. It was also demonstrated that the free or uncomplexed metal ion potential $(E(\mathrm{M}))$ for the metal ion of interest, a critical parameter for calculating formation constants determined by polarography, could be more accurately determined by relating it to the free $\mathrm{Tl}(\mathrm{I})$ potential $(E(\mathrm{Tl}))$. [13]

When studying the $\mathrm{Cd}(\mathrm{II})$ picolinic acid system starting from $\mathrm{pH} 0.3$, a novel MLH species was found to exist in the low $\mathrm{pH}$ region. Even though it was a minor species in solution under the conditions used which resulted in only about a $2 \mathrm{mV}$ shift, with the accurate compensation for $E_{\mathrm{j}}$ (as well as taking the effect of the changing ionic strength on the reduction potentials of the metals ions into account) information about this species was not lost. To support the existence of this species, a crystal was grown from an acidic solution with $\mathrm{Cd}(\mathrm{II})$ and picolinic acid concentrations such that the MLH species would be dominant in solution. The crystal structure showed that the pyridine nitrogen was protonated and the Cd(II) was bound to the two carboxylate oxygen atoms, indicating the MLH species. [15] This demonstrates the robustness of the strategies developed and the protocols used to interpret polarographic data to study metal-ligand equilibria in general and under very acidic conditions in particular.

In order to fully test these procedures, the $\mathrm{Cu}(\mathrm{II})$ picolinic acid system was selected because the $\mathrm{CuL}$ species exists at $\mathrm{pH} 0$ already. Since $\log \beta$ for $\mathrm{CuL}$ has been established (by other techniques) and recommended values are quoted in the NIST database [14] containing critically assessed literature data, it was decided to evaluate the $\log \beta$ values for both $\mathrm{CuL}$ and $\mathrm{CuL}_{2}$ by polarography and compare it to these values.

A further complication arose as $\mathrm{Cu}$ (II) was not reversibly reduced in nitrate solutions, the background anion utilised in this work. The kinetic properties of the electron transfer process had to be considered as the reversible reduction potentials are required to apply the theories leading to the rigorous evaluation of stability constants. [16, 17] The additional aim was thus to find the most suitable protocol to determine the reversible half-wave potential from quasi-reversible DC waves and several approaches were considered.

\section{Experimental}

\subsection{Materials}

All reagents were analytical grade. Stock solutions of $0.100 \mathrm{M} \mathrm{Tl}(\mathrm{I})$ nitrate and $0.100 \mathrm{M} \mathrm{Cu}(\mathrm{II})$ nitrate were both made up in $0.5 \mathrm{M} \mathrm{HNO}_{3}$. Deionized water of resistivity $18 \mathrm{M} \Omega \mathrm{cm}$ was always used.

\subsection{Instrumentation}


Polarographic experiments were carried out using the same cell and automated instrumental setup as previously described [13]. Sampled DC polarography was employed with a step time of $1 \mathrm{~s}$, a current integration time of $60 \mathrm{~ms}$ and a step potential of $4 \mathrm{mV}$.

The kind of a glass electrode (GE) which was found to work exceptionally well in highly acidic medium (Metrohm cat. no. 6.0234.100) [2], was calibrated by the titration of standardised solutions of $0.5 \mathrm{M} \mathrm{HNO}_{3}$ with $0.5 \mathrm{M} \mathrm{NaOH}$ and the calibration plot was calculated. Because the accurate measurement of $\mathrm{pH}$ is critical in this work, a deviation from linearity of the GE response in the very acidic region had to be accounted for. To this effect, a quadratic function was fitted to experimentally recorded GE potential readings in the highly acidic region to minimise $E_{\mathrm{j}}$ errors [2]. In this work $\mathrm{pH}$ signifies $\log \left[\mathrm{H}^{+}\right]$.

\subsection{Procedure}

Three types of experiments were run as fully described before. [13] Firstly, to investigate the variation in $E_{\mathrm{j}}$ with $\mathrm{pH}$, several polarographic $\mathrm{pH}$ titration experiments were performed in a solution containing $0.5 \mathrm{M} \mathrm{HNO}_{3}$ and the two metals ions, $9.97 \times 10^{-5} \mathrm{M} \mathrm{Cu}(\mathrm{II})$ and $1.99 \times 10^{-4} \mathrm{M}$ $\mathrm{Tl}(\mathrm{I})$, in the absence of ligand. Secondly, $\mathrm{Cu}(\mathrm{II})$-picolinic acid equilibria were studied by polarographic $\mathrm{pH}$ titration, where initial solutions were the same as above. To this effect, solid picolinic acid was added such that the total ligand-to- $\mathrm{Cu}$ (II) concentration ratios were 32, 103 and 207 for three separate experiments. In all these polarographic $\mathrm{pH}$ titrations, the titrant was $0.5 \mathrm{M} \mathrm{NaOH}$ and the $\mathrm{pH}$ step was about 0.1 . At each $\mathrm{pH}$ step a polarogram and the GE potential were recorded and selected polarograms are shown in Fig. S1a. Thirdly, $\mathrm{Cu}(\mathrm{II})$-picolinic acid equilibria were studied by polarographic ligand titration in three separate experiments at $\mathrm{pH} 0.47,0.90$ and 1.37. In this case the initial solution consisted of a mixture of $0.5 \mathrm{M} \mathrm{HNO}_{3}, 0.5$ $\mathrm{M} \mathrm{NaOH}$ and $9.97 \times 10^{-5} \mathrm{M} \mathrm{Cu}(\mathrm{II})$ such that the required $\mathrm{pH}$ was attained. The titrant was a $0.5 \mathrm{M}$ picolinic acid solution adjusted to the same $\mathrm{pH}$ as the test solution and the total ligand-to- $\mathrm{Cu}(\mathrm{II})$ concentration ratios were varied stepwise between 20 and 200 with a polarogram recorded at each step (see Fig. S1b for selected polarograms). The $\mathrm{pH}$ was kept constant throughout the titration by adding a few $\mu \mathrm{L}$ of $0.5 \mathrm{M} \mathrm{NaOH}$ as required.

Experimental half-wave potentials $\left(E_{1 / 2}\right)$ and diffusion limited currents $\left(I_{\mathrm{d}}\right)$ were obtained by fitting the DC reduction waves, recorded at each step in the titration experiments, using Eq. 1 [18]:

$$
f\left(E_{\text {app }}\right)=\frac{I_{\mathrm{d}}}{\exp (n \delta F / R T)\left(E_{\text {app }}-E_{1 / 2}\right)+1}+I_{\mathrm{b}}
$$

where $E_{\text {appl }}$ refers to the applied potential, $I_{\mathrm{b}}$ is the background current, $n$ is the number of electrons transferred and $\delta$ measures the steepness of the reduction wave and should be unity for reversible electron transfer processes. The reduction waves for $\mathrm{Cu}(\mathrm{II})$ and $\mathrm{Tl}(\mathrm{I})$ were fitted separately. The function used to describe the background current was $I_{\mathrm{b}}=a+b E_{\text {appl }}+c \exp \left(d \times E_{\text {appl }}\right)$, where the exponential term accounted for the onset of mercury oxidation when fitting the $\mathrm{Cu}(\mathrm{II})$ wave or hydrogen evolution when fitting the $\mathrm{Tl}(\mathrm{I})$ wave. Mercury oxidation should ideally be avoided, but its close proximity to $\mathrm{Cu}(\mathrm{II})$ reduction made it impossible to evade completely. The reduction of $\mathrm{Tl}(\mathrm{I})$ was fully reversible across the $\mathrm{pH}$ range, so $\delta$ was set equal to one in this case. This was not so for the $\mathrm{Cu}(\mathrm{II})$ reduction with $\delta$ values varying between 1 and 0.6. The $E_{1 / 2}$ values obtained from Eq. 1 were thus for the quasi-reversible process $\left(E_{1 / 2}^{\mathrm{q}}\right)$.

Methods employed to determine the reversible $E_{1 / 2}$ values $\left(E_{1 / 2}^{\mathrm{r}}\right)$ from these quasi-reversible polarograms were investigated so that stability constants could be accurately calculated. Once reversible $E_{1 / 2}$ values were determined and were corrected for $E_{\mathrm{j}}$ where necessary, the polarographic data were treated as previously described in detail $[13,17]$ to evaluate stability constants using the following relationship:

$$
\left\{E(\mathrm{M})-E\left(\mathrm{M}_{\text {comp }}\right)_{(\mathrm{i})}\right\}-\frac{R T}{n F} \ln \frac{I\left(\mathrm{M}_{\text {comp }}\right)_{(\mathrm{i})}}{I(\mathrm{M})_{(\mathrm{i})}}=\frac{R T}{n F} \ln \frac{\left[\mathrm{M}_{\mathrm{T}}\right]_{(\mathrm{i})}}{\left[\mathrm{M}_{(\mathrm{i})}\right.}
$$

where (i) indicates the experimental values at either each $\mathrm{pH}$ step or after each addition of ligand solution, depending on the type of titration performed. All other symbols used are listed and defined in the Appendix. The left side of the equation (also called the corrected potential shift) is calculated from the experimentally determined values derived from the measured polarograms. When plotted vs. $\mathrm{pH}$ or $\log [\mathrm{L}]$ it gives the experimental complex formation curve (ECFC). The right side of the equation, called the calculated complex formation curve (CCFC) when plotted vs. pH or $\log [\mathrm{L}]$, involves solving for mass balance equations to determine $[\mathrm{M}]$ at each point in the titration. The stability constants for the $\mathrm{Cu}$ (II)-picolinic acid species were refined such that the difference between the ECFC and CCFC is minimised, while those given in Table 2 a were kept constant. This was achieved using dedicated software called 3D-CFC. [19]

\section{Results and Discussion}




\subsection{Determining reversible half-wave potentials for $\mathrm{Cu}$ (II) from quasi-reversible polarograms}

It is well known that the extent of reversibility of an electron transfer process can be assessed from a DC wave by the plot of $\log \left\{I /\left(I_{\mathrm{d}}-I\right)\right\}$ against $E_{\text {appl. }}$. A fully reversible process would produce a straight line of slope $0.05916 / n \mathrm{~V}$ at $25{ }^{\circ} \mathrm{C}$ and for an irreversible process the magnitude of the slope would be smaller. The plot would not be linear for a quasi-reversible electron transfer process. [18] Alternatively, the value of $\delta$ obtained from fitting the DC wave (Eq. 1) gives a good indication. It has been suggested that for $1<\delta<0.9$ the electron transfer process can be regarded as fully reversible for our application, for $0.9<\delta<0.5$ the process is quasireversible and for $\delta<0.5$ the process is irreversible. [20]

The reduction of $\mathrm{Cu}(\mathrm{II})$ in nitrate and perchlorate background electrolytes depends on both the $\mathrm{pH}$ [21-23] and the ionic strength $[23,24]$ of the solution. Studies have been performed using cyclic voltammetry [23,24], as well as alternating current (AC) [22] and direct current (DC) [21] polarography to explain these observations. It was demonstrated that as the $\mathrm{pH}$ was increased, the degree of reversibility also increased for the reduction of $\mathrm{Cu}$ (II) in both perchlorate and nitrate media by cyclic voltammetry. [23] Additionally, the reduction kinetics of $\mathrm{Cu}$ (II) in nitrate solutions is faster than that in perchlorate solutions and the reduction becomes less reversible in lower ionic strength solutions. [24]

In Fig. S2 it is seen that when picolinic acid is absent from the solution in a $\mathrm{pH}$ titration, the decrease in the value of $\delta$ for $\mathrm{Cu}$ (II) reduction follows a similar trend to the decrease in ionic strength during the titration (from about $0.5 \mathrm{M}$ to about $0.25 \mathrm{M}$ ) even though the $\mathrm{pH}$ is increasing. This indicates that nitrate plays a role in the reduction process, although the exact mechanism is not fully understood, and that the effect of the ionic strength is greater than that of $\mathrm{pH}$. Unfortunately working in very acidic solutions and at relatively low ionic strength does not allow for the addition of a supporting salt electrolyte to maintain a constant ionic strength. These titrations were terminated before hydrolysis of $\mathrm{Cu}(\mathrm{II})$ could take place, so hydrolysis products did not play a role in the extent of reversibility, as has been shown to occur. [2123] After chelation of $\mathrm{Cu}$ (II) by picolinic acid, the electron transfer rate was slightly enhanced, but still remained quasi-reversible over much of the $\mathrm{pH}$ range (see Fig. S2). Various approaches to determine the $E_{1 / 2}^{\mathrm{r}}$ from a quasi-reversible reduction wave were considered.

Using the curved plot of $\log \left\{I /\left(I_{\mathrm{d}}-I\right)\right\}$ vs. $E_{\text {appl }}$ for a quasi-reversible DC polarogram, Koryta extrapolated the asymptote from the foot of the wave to the $E_{\text {appl-axis and }}$ the value at the intercept corresponded to $E_{1 / 2}^{\mathrm{r}}$. [25,26]
In this work, even after the background currents were subtracted, the clear curvature as presented in literature examples was not obvious. Deciding where to draw the asymptote was problematic and resulted in predicted $E_{1 / 2}^{\mathrm{r}}$ values varying by more than $10 \mathrm{mV}$ (see Fig. S3).

Cukrowski and Zhang [27] estimated the value of $E_{1 / 2}^{\mathrm{r}}$ from the quasi-reversible polarogram itself. The polarogram was first fitted using Eq. 1 to obtain the values of $I_{\mathrm{d}}$ and the variables for the background current. (The half-wave potentials determined where $\delta<0.9$ refer to $E_{1 / 2}^{\mathrm{q}}$.) The polarogram was then refitted by first setting $\delta=1$ and removing data points at the top part of the reduction wave where the current was still increasing (before the diffusion limited current was reached) so that the fitted curve passed through all remaining points, particularly those at the foot of the wave and where the current is diffusion limited. The only parameter refined in this case was $E_{1 / 2}$, which should now correspond to $E_{1 / 2}^{\mathrm{r}}$ (see Fig. 1).

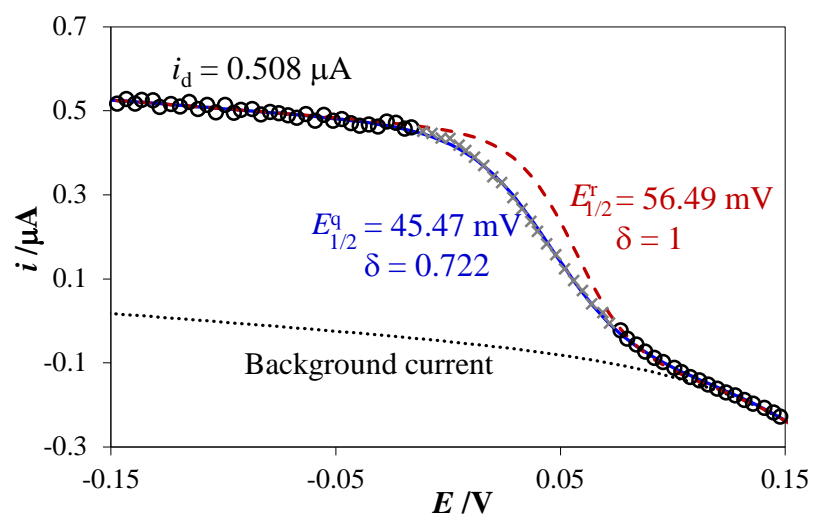

Fig. 1. Polarogram for the reduction of $\mathrm{Cu}$ (II) at $\mathrm{pH} 1.51$. The polarogram was fitted using Eq (1) through (i) all points (-) and (ii) only points indicated by $\bigcirc$ while fixing $\delta=1$ (---) to estimate $E_{1 / 2}^{\mathrm{r}}$.

Fig. 2a shows both $E_{1 / 2}^{\mathrm{q}}$ and $E_{1 / 2}^{\mathrm{r}}$ values determined for a $\mathrm{pH}$ titration without picolinic acid present. Additionally, since it has been shown that $E_{\mathrm{j}}$ values calculated using the Henderson equation approximated those determined polarographically fairly well [13], $E_{1 / 2}^{\mathrm{r}}$ values for $\mathrm{Cu}$ (II) reduction were predicted as a function of $\mathrm{pH}$ by subtracting the calculated $E_{\mathrm{j}}$ values from the potential of free $\mathrm{Cu}(\mathrm{II})(E(\mathrm{Cu}))$ (determined as discussed in Section 3.2). Fig. 2a demonstrates that the $E_{1 / 2}^{\mathrm{r}}$ values determined by the method proposed by Cukrowski and Zhang [27] follow this predicted trend. As expected from the decreasing $\delta$ values, there is only a small difference between $E_{1 / 2}^{\mathrm{q}}$ and $E_{1 / 2}^{\mathrm{r}}$ at the lowest $\mathrm{pH}$ where $\delta$ is 
closest to unity and the difference increases with increasing $\mathrm{pH}$.
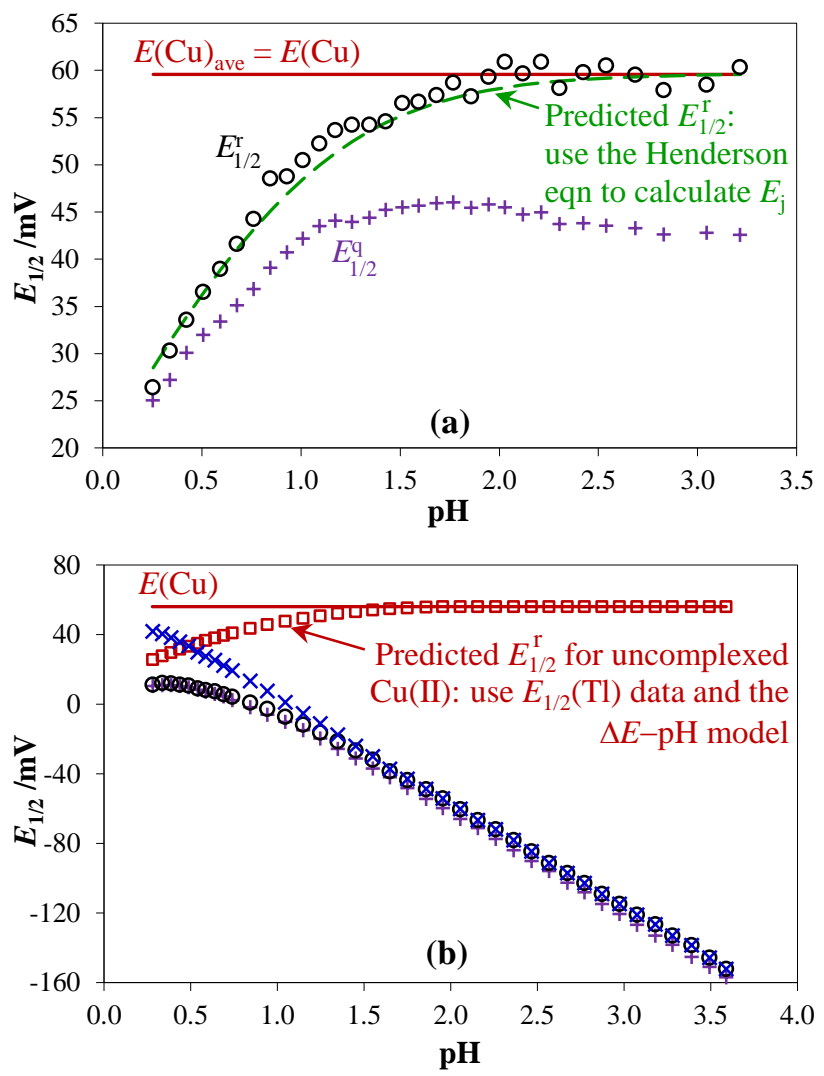

Fig. 2. Comparison of experimentally recorded $E_{1 / 2}^{\mathrm{q}}$ values (+) and $E_{1 / 2}^{\mathrm{r}}$ values $(\mathrm{O})$, as determined using the procedure by Cukrowski and Zhang [23], for the reduction of $\mathrm{Cu}$ (II) in a $\mathrm{pH}$ titration in (a) the absence and (b) the presence of picolinic acid ([L]:[Cu(II)] = 103). The predicted $E_{1 / 2}^{\mathrm{r}}$ values for uncomplexed $\mathrm{Cu}(\mathrm{II})$ without $E_{\mathrm{j}}$ correction are shown in (a) as (---) obtained by subtracting $E_{\mathrm{j}}$, calculated using the Henderson equation, from $E(\mathrm{Cu})$ and in (b) as $(\square)$ as determined from the $E(\mathrm{Tl})$ data and the $\Delta E-\mathrm{pH}$ model. In (b) the $E_{1 / 2}^{\mathrm{r}}$ values after accounting for $E_{\mathrm{j}}(\times)$ (as determined from the $\mathrm{Tl}(\mathrm{I})$ data) are also indicated.

Ružić et al. [26] also described how both $E_{1 / 2}^{\mathrm{r}}$ and $E_{1 / 2}^{\mathrm{i}}$ (the irreversible half-wave potential) could be determined graphically from the log plot described above. Since graphical analysis proved impossible here, the methodology used by Cukrowski et al. [20] was considered. They discuss how the expression derived by Ružić et al. [26] was rearranged and the background current included giving the relationship:

$$
I=\frac{I_{\mathrm{d}}}{\exp (n F / R T)\left(E_{\text {appl }}-E_{1 / 2}^{\mathrm{r}}\right)+\exp (\alpha n F / R T)\left(E_{\text {appl }}-E_{1 / 2}^{\mathrm{i}}\right)+1}+I_{\mathrm{b}}
$$

where $\alpha$ is the cathodic transfer coefficient. Eq. 3 was used to fit the quasi-reversible DC polarograms (using non-linear curve fitting) to determine $I_{\mathrm{d}}$ and $E_{1 / 2}^{\mathrm{r}}$ (as well as $E_{1 / 2}^{\mathrm{i}}, \alpha$ and parameters for the background current). In order to reduce the number of variables when fitting these functions, the values of $I_{\mathrm{d}}$ and the background current variables were kept the same as those determined when applying Eq. 1. In this work it was found that the values of $E_{1 / 2}^{\mathrm{r}}$ predicted by Eq. 3 followed no particular trend and were not meaningful (values of up to $15 \mathrm{~V}$ were found) and the values of $E_{1 / 2}^{\mathrm{i}}$ were similar to those for $E_{1 / 2}^{\mathrm{q}}$.

Matsuda and Ayabe [28-30] also used the log plot to determine both $E_{1 / 2}^{\mathrm{r}}$, and in a similar fashion, Mkwizu [31] rearranged their derived expression to give:

$$
I=\frac{I_{\mathrm{d}}}{\exp (n F / R T)\left(E_{\text {appl }}-E_{1 / 2}^{\mathrm{r}}\right)+\Gamma \exp (\alpha n F / R T)\left(E_{\text {appl }}-E_{1 / 2}^{\mathrm{r}}\right)+1}+I_{\mathrm{b}}
$$

where $\Gamma=1.13 / \Lambda \tau^{1 / 2} ; \tau$ is the drop life time and $\Lambda$ is a kinetic parameter which includes the heterogeneous rate constants and is described for both simple or complexed metal ions. Eq 4 was used to fit the quasi-reversible DC polarograms (using non-linear curve fitting as before) to determine $I_{\mathrm{d}}$ and $E_{1 / 2}^{\mathrm{r}}$ (as well as $\alpha, \Gamma$ and parameters for the background current). Unlike Matsuda and Ayabe [28-30], $\Gamma$ was refined as a single value in this case and the $I_{\mathrm{d}}$ and the background current variables were kept the same as those determined when applying Eq. 1 . The $E_{1 / 2}^{\mathrm{r}}$ values predicted by Eq. 4 range between $50 \mathrm{mV}$ and 135 $\mathrm{mV}$, thus giving significantly higher values than expected and the $E_{1 / 2}^{\mathrm{r}}-\mathrm{pH}$ plot did not follow the trend predicted from calculated $E_{\mathrm{j}}$ values. The reason for these two fitting procedures failing in this case is unclear, but could be due to the close proximity of the mercury oxidation wave to the reduction wave of $\mathrm{Cu}(\mathrm{II})$.

The approach by Cukrowski and Zhang [27] was the most successful method for determining $E_{1 / 2}^{\mathrm{r}}$ from quasireversible DC waves in this work and these values were used in further calculations throughout.

\subsection{Modelling the difference in $E_{1 / 2}^{\mathrm{r}}$ values for $\mathrm{Cu}(\mathrm{II})$ and $\mathrm{Tl}(\mathrm{I})$}

Using data from $\mathrm{pH}$ titrations, where the ligand was omitted, the difference in the $E_{1 / 2}^{\mathrm{r}}$ values for $\mathrm{Cu}(\mathrm{II})$ and $\mathrm{Tl}(\mathrm{I})$ was modeled as a function of $\mathrm{pH}$, as described before. [13] Firstly, the $E_{1 / 2}^{\mathrm{r}}$ values in the $\mathrm{pH}$ region where $E_{\mathrm{j}}$ is constant (above about $\mathrm{pH} 2$ ) were averaged to give $E(\mathrm{M})_{\text {ave }}$ which is equivalent to the free metal ion potential $(E(\mathrm{M}))$. The difference $\Delta E(\mathrm{M})_{\text {ave }}=E(\mathrm{Cu})_{\text {ave }}-$ $E(\mathrm{Tl})_{\text {ave }}$ was calculated as $487.7 \pm 0.3 \mathrm{mV}$ (for five experiments). For a titration including picolinic acid, $E(\mathrm{Cu})$ was then evaluated by adding $E(\mathrm{Tl})_{\text {ave }}$ (determined from the same experiment) to $\Delta E(\mathrm{M})_{\mathrm{ave}}$. Interestingly, 
the reference electrode used to collect one of the data sets was problematic in that the potential was shifted almost $200 \mathrm{mV}$ too positive, but the $\Delta E(\mathrm{M})_{\text {ave }}$ calculated was still within the range of the other experiments. This demonstrates how the $\mathrm{Tl}(\mathrm{I})$ potential data could act as an internal reference to the potential measurements of the metal ion of interest.

Secondly, the difference in the $E_{1 / 2}^{\mathrm{r}}$ values for the two metal ions in the $\mathrm{pH}$ region where $E_{\mathrm{j}}$ varied with $\mathrm{pH}$ (below about $\mathrm{pH}$ 2) was determined for all five data sets (i.e. $\left.\Delta E_{1 / 2}(\mathrm{M})=E_{1 / 2}^{\mathrm{r}}(\mathrm{Cu})-E_{1 / 2}(\mathrm{Tl})\right)$. This was necessary to account for slight differences in shifts in $E_{1 / 2}$ for $\mathrm{Cu}$ (II) and $\mathrm{Tl}(\mathrm{I})$ due to the decreasing ionic strength (from $0.5 \mathrm{M}$ to about $0.25 \mathrm{M}$ ) during the titration. To test the effect of changing ionic strength on the reduction potentials, solutions containing $\mathrm{Tl}(\mathrm{I})$ and $\mathrm{Cu}(\mathrm{II})$ were made up in either $0.5 \mathrm{M}$ or $0.25 \mathrm{M} \mathrm{KNO}_{3}$, polarograms were recorded and the $E_{1 / 2}^{\mathrm{r}}$ values were determined. The difference in these $E_{1 / 2}^{\mathrm{r}}$ values for $\mathrm{Cu}$ (II) (i.e. $\left.\Delta_{\mu} E_{1 / 2}(\mathrm{Cu})_{0.5-0.25}\right)$ was $-0.8 \mathrm{mV}$ and $\Delta_{\mu} E_{1 / 2}(\mathrm{Tl})_{0.5-0.25}$ was $-2.3 \mathrm{mV}$, indicating that $\Delta_{\mu} E_{1 / 2}(\mathrm{M})_{0.5-0.25}$ is different for the two metal ions. The average $\Delta E_{1 / 2}(\mathrm{M})-\mathrm{pH}$ relationship was modelled by a fifth order polynomial (see Fig. S4). Above $\mathrm{pH} \mathrm{2.7,} \Delta E_{1 / 2}(\mathrm{M})$ was set equal to $\Delta E(\mathrm{M})_{\text {ave }}$, although no significant change in $\Delta E_{1 / 2}(\mathrm{M})$ was observed from $\mathrm{pH} 1.8$ already.

Since $\mathrm{pH}$ titrations were started at $\mathrm{pH} 0.3, E_{j}$ had to be corrected in the very acidic region. Using the $\Delta E_{1 / 2}(\mathrm{M})-\mathrm{pH}$ model and the $E_{1 / 2}(\mathrm{Tl})$ data collected when ligand is present in the test solution, the magnitude of $E_{\mathrm{j}}$ can be calculated. An example of the measured and corrected $E_{1 / 2}$ values for a titration with picolinic acid present in the test solution is shown in Fig. 2b. The value of $E(\mathrm{Cu})$ can also be determined using $E(\mathrm{Tl})_{\text {ave }}$ and $\Delta E(\mathrm{M})_{\text {ave }}$.

\subsection{Equilibria studies of the $\mathrm{Cu}(\mathrm{II})$-picolinic acid system}

When performing a $\mathrm{pH}$ titration experiment, the addition of picolinic acid to the test solution at $\mathrm{pH} 0.3$ (containing and $\mathrm{Cu}(\mathrm{II})$ and $\mathrm{Tl}(\mathrm{I})$ ), results in a negative shift in the reduction potential for $\mathrm{Cu}(\mathrm{II})$ demonstrating that complex formation takes place at this low $\mathrm{pH}$ already. When comparing the diffusion limited currents of the $\mathrm{Cu}(\mathrm{II})$ picolinic acid complexes to that expected for uncomplexed $\mathrm{Cu}$ (II) throughout the entire titration, the values compared well indicating that the rates of diffusion are very similar. The difference between $E(\mathrm{Cu})$ and $E\left(\mathrm{Cu}_{\text {comp }}\right)(\Delta E)$, that had been corrected for $E_{\mathrm{j}}$ where necessary, is thus the main factor in establishing the formation constants. It is clear that any error in (i) the $E_{1 / 2}^{\mathrm{r}}$ values determined for a quasi-reversible process, (ii) the magnitude of $E_{\mathrm{j}}$ or (iii) the value of $E(\mathrm{Cu})$, would affect the formation constants.

Slope analysis was done using the ECFCs to predict the metal-ligand species formed. A slope close to $60 \mathrm{mV} / \mathrm{pH}$ was found across the $\mathrm{pH}$ range. Given that the slope is approximately $60 / n \times$ number of protons involved in the reaction, this indicates that $\mathrm{CuL}^{+}$forms at low $\mathrm{pH}$ where $\mathrm{H}_{2} \mathrm{~L}^{+}$is the dominant form of the ligand and $\mathrm{CuL}_{2}$ forms where HL is predominant in solution. When both these species were included in the model and the stability constants were refined, the CCFCs fitted the experimental data well (see Fig. 3a).

The average $\log \beta$ values determined for the $\mathrm{pH}$ titrations are given in Table $2 \mathrm{~b}$. The larger standard deviation noted for the $\mathrm{CuL}^{+}$species was probably due to its formation in the $\mathrm{pH}$ region where the junction potential had to be accounted for. As seen from the species distribution diagram in Fig. $3 \mathrm{c}$ for $[\mathrm{L}]:[\mathrm{Cu}(\mathrm{II})]=$ $100, \mathrm{CuL}^{+}$is only present under very acidic conditions with insignificant concentrations existing above $\mathrm{pH} 2$. Additionally, data carries more weight in the refinement process when the concentration of a species increases with increasing $\mathrm{pH}$; for $\mathrm{CuL}^{+}$this occurs below $\mathrm{pH} 0.3$ (the $\mathrm{pH}$ from where measurements were started). That being said, the values compared very well to the critically assessed literature values given in the NIST Database. [14] The $\mathrm{CuL}_{2}$ species predominates over a wide $\mathrm{pH}$ range and is the only species present from about $\mathrm{pH} 2.5$ to $\mathrm{pH} 14$ under these conditions. The larger difference between the literature $\log \beta$ value for $\mathrm{CuL}_{2}$ and that determined here is most likely due to more inaccurate $E_{1 / 2}^{\mathrm{r}}$ values being estimated where $\delta$ is at its lowest, especially considering the rudimentary method used to calculate these values.

Table 2. (a) The dissociation constant for water, the stepwise protonation constants for picolinic acid and the overall stability constants for $\mathrm{Cu}(\mathrm{II})$ hydroxides at $25^{\circ} \mathrm{C}$ and $0.5 \mathrm{M}$ ionic strength. [14] (The value in brackets is uncertain.) (b) Stability constants for $\mathrm{Cu}(\mathrm{II})$-picolinic acid complexes determined using polarography at $25^{\circ} \mathrm{C}$ and ionic strength $0.25-0.5 \mathrm{M}$. Literature data are reported at $25^{\circ} \mathrm{C}$ and the indicated ionic strength.

\begin{tabular}{lll}
\hline (a) Equilibrium & $\log \boldsymbol{K}$ & \\
\hline $\mathrm{H}_{2} \mathrm{O} \leftrightarrow \mathrm{H}^{+}+\mathrm{OH}^{-}$ & -13.74 & \\
$\mathrm{~L}^{-}+\mathrm{H}^{+} \leftrightarrow \mathrm{HL}$ & 5.18 & \\
$\mathrm{HL}+\mathrm{H}^{+} \leftrightarrow \mathrm{H}_{2} \mathrm{~L}^{+}$ & $(0.86)$ & \\
$\mathrm{Cu}^{2+}+\mathrm{OH}^{-} \leftrightarrow \mathrm{Cu}(\mathrm{OH})^{+}$ & 6.1 & \\
$2 \mathrm{Cu}^{2+}+\mathrm{OH}^{-} \leftrightarrow \mathrm{Cu}_{2}(\mathrm{OH})^{3+}$ & $7.7[\mathrm{a}]$ & \\
$2 \mathrm{Cu}^{2+}+2 \mathrm{OH}^{-} \leftrightarrow \mathrm{Cu}_{2}(\mathrm{OH})_{2}{ }^{2+}$ & 16.7 & \\
$3 \mathrm{Cu}^{2+}+4 \mathrm{OH}^{-} \leftrightarrow \mathrm{Cu}_{3}(\mathrm{OH})_{4}{ }^{2+}$ & $33.7[\mathrm{~b}]$ & \\
\hline (b) This work & $\log \beta_{1}$ & $\log \beta_{2}$ \\
\hline pH titration & $7.75 \pm 0.14$ & $14.88 \pm 0.05$ \\
Ligand titration & $7.74 \pm 0.05$ & $14.69 \pm 0.06$ \\
\hline Literature [14] & $\log \beta_{1}$ & $\log \beta_{2}$ \\
\hline
\end{tabular}




$\begin{array}{lll}\mu=0.1 \mathrm{M} & 7.87 & 14.78 \\ \mu=0.5 \mathrm{M} & & 14.70 \\ \mu=1.0 \mathrm{M} & 7.7 & 14.5\end{array}$

[a] $\log K$ value for $3 \mathrm{M}$ ionic strength. [b] $\log K$ value for $0.1 \mathrm{M}$ ionic strength.
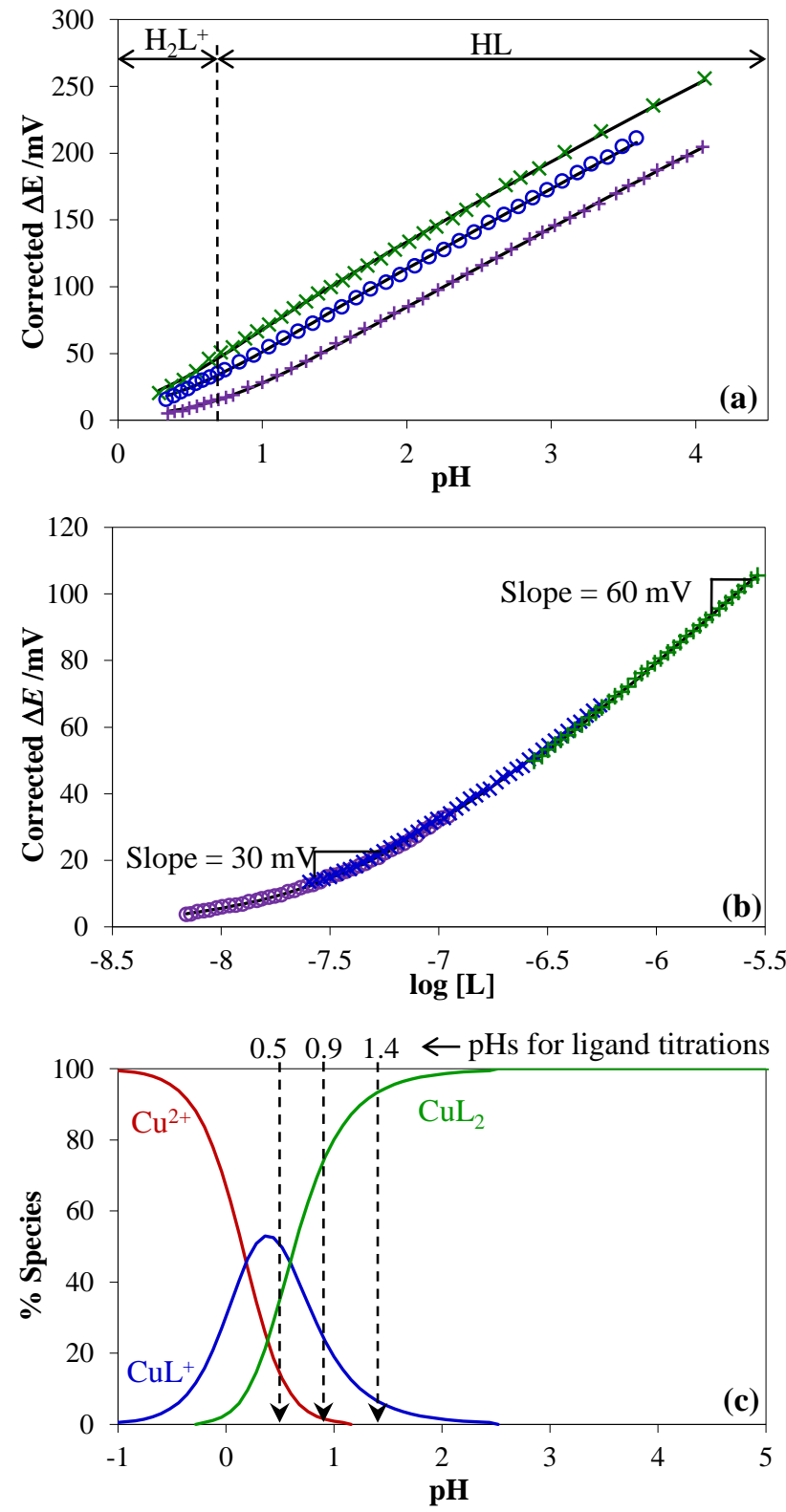

Fig. 3. Comparison of the ECFCs and corresponding CCFCs (-) calculated using the species model $\mathrm{CuL}^{+}$and $\mathrm{CuL}_{2}$ for (a) $\mathrm{pH}$ titrations where [L]:[Cu(II)] is $32(+), 103(\bigcirc)$ and $207(\times)$ (the $\mathrm{pH}$ region with the major form of the ligand is also indicated); and (b) ligand titrations at $\mathrm{pH} 0.47(\mathrm{O}), 0.90(\times)$ and 1.37 (+) and slopes are indicated. (c) Species distribution diagram for the $\mathrm{Cu}(\mathrm{II})$-picolinic acid system where $[\mathrm{Cu}(\mathrm{II})]=$ $1 \times 10^{-4} \mathrm{M}$ and $[\mathrm{L}]=1 \times 10^{-2} \mathrm{M}$. The arrows demarcate the $\mathrm{pHs}$ at which ligand titrations were performed.
Three ligand titrations were performed at the $\mathrm{pHs}$ indicated in Fig. 3c. The very acidic conditions were used in order to glean information about both the ML and $\mathrm{ML}_{2}$ species. A small drift in $\mathrm{pH}$ is often observed during a ligand titration and is generally tolerable, but since a fairly big change in $E_{\mathrm{j}}$ occurs with a small change in $\mathrm{pH}$ at these very low $\mathrm{pHs}$, the variation was not allowed and the $\mathrm{pH}$ was adjusted as necessary. In hindsight, the $E_{1 / 2}(\mathrm{Tl})$ values could have been used to account for variations in $E_{\mathrm{j}}$. When the $\Delta E$ values are calculated to determine stability constants, $E_{\mathrm{j}}$ will be negated provided the solution $\mathrm{pH}$ remains constant throughout the experiment. The extent of reversibility did not change much during a titration as the ionic strength remained fairly constant due to very little dilution taking place. Also the $\delta$ values were close to 0.9 and the $E_{1 / 2}^{\mathrm{r}}$ values determined were thus close to the $E_{1 / 2}^{\mathrm{q}}$ values.

Slope analysis of the ECFCs are displayed in Fig. $3 \mathrm{~b}$ where the slope is approximately $60 / n \times$ number of free ligand molecules involved in the reaction for ligand titrations. This analysis again indicated that $\mathrm{CuL}^{+}$and $\mathrm{CuL}_{2}$ were the major species formed. The calculated curves fitted the experimental data well and the refined $\log \beta$ values, presented in Table $2 \mathrm{~b}$, compared well to the literature values.

\subsection{Evaluation of errors had corrections implemented been ignored}

In this work, two main sources of error were considered, namely the diffusion junction potential and the quasireversible nature of the $\mathrm{Cu}$ (II) reduction waves. To assess the effects when neglecting to correct for these factors in $\mathrm{pH}$ titration experiments, stability constants were calculated where (i) the $E_{1 / 2}^{\mathrm{r}}(\mathrm{Cu})$ values were determined but $E_{\mathrm{j}}$ was not accounted for and (ii) $E_{\mathrm{j}}$ was corrected for but the $E_{1 / 2}^{\mathrm{q}}$ values were used.

In the first case, when ignoring $E_{\mathrm{j}}$, this would not only affect the $E\left(\mathrm{M}_{\text {comp }}\right)$ values determined below $\mathrm{pH} 2$ where $E_{\mathrm{j}}$ varies with $\mathrm{pH}$, but since the free $\mathrm{Cu}(\mathrm{II})$ potential is measured in the most acidic solution before ligand is added, $E(\mathrm{Cu})$ would also be underestimated by about 30 $\mathrm{mV}$ (see Fig. 2b). Because the shift in potential due to complexation $\left(E(\mathrm{M})-E\left(\mathrm{M}_{\text {comp }}\right)\right)$ is used in determining stability constants (see Eq. 2), it implies that not only will the stability constants for species formed below $\mathrm{pH} 2$ be affected, but all stability constants will contain error. Using the $E_{1 / 2}^{\mathrm{r}}(\mathrm{Cu})$ values, data was analysed without making corrections for $E_{\mathrm{j}}$ and the average $\log \beta$ obtained are given in Table 3 (For a more detailed analysis see Table S1). The very large standard deviation for the 
$\mathrm{CuL}^{+}$species is mainly due to the apparent onset of complex formation occurring at much higher $\mathrm{pHs}$. This is especially so for the $[\mathrm{L}]:[\mathrm{Cu}(\mathrm{II})]=32$ experiment where the corrected $\Delta E$ values are below zero up to $\mathrm{pH}$ 0.90 due to the underestimated $E(\mathrm{Cu})$ value and the smaller potential shifts observed for the lower [L]: $[\mathrm{Cu}(\mathrm{II})]$ ratio (see Fig 4a). The $\log \beta$ values for both species are thus significantly lower than those quoted in Table 2b.

Table 3. $\log \beta$ values calculated for $\mathrm{CuL}^{+}$and $\mathrm{CuL}_{2}$ when correcting for either the non-reversible reduction of $\mathrm{Cu}(\mathrm{II})$ species or $E_{\mathrm{j}}$ or both. When $E_{1 / 2}^{\mathrm{q}}$ values were used, the $\mathrm{CuL}_{3}{ }^{-}$ species could also be included in the model.

\begin{tabular}{llll}
\hline Corrections & $\log \beta_{1}$ & $\log \beta_{2}$ & $\log \beta_{3}$ \\
\hline Use $E_{1 / 2}^{\mathrm{r}}$ (no $E_{\mathrm{j}}$ correction) & 7.26 & 13.84 & \\
Account for $E_{\mathrm{j}}$ (use $E_{1 / 2}^{\mathrm{q}}$ ) & \pm 0.69 & \pm 0.12 & \\
& \pm 0.66 & 15.04 & \\
Account for $E_{\mathrm{j}}$ (use $E_{1 / 2}^{\mathrm{q}}$ ) & 7.57 & 15.08 & \\
& \pm 0.51 & \pm 0.08 & 18.35 \\
Account for $E_{\mathrm{j}}$ and use $E_{1 / 2}^{\mathrm{r}}$ & 7.75 & 14.88 & \\
& \pm 0.14 & \pm 0.05 & \\
\hline
\end{tabular}

In the second case, after accounting for $E_{\mathrm{j}}$, the effect of using the $E_{1 / 2}^{\mathrm{q}}(\mathrm{Cu})$ values rather than the $E_{1 / 2}^{\mathrm{r}}(\mathrm{Cu})$ values when determining stability constants was considered. Because the deviation from reversibility increased as the titration proceeded (and hence as the $\mathrm{pH}$ increased), it was expected that larger errors would be obtained for the $\mathrm{CuL}_{2}$ species in this case. Additionally, since the $E_{1 / 2}^{\mathrm{q}}$ values are more negative than the $E_{1 / 2}^{\mathrm{r}}$ values, it was envisaged that the the stablity constants would be higher due to larger calculated $\Delta E$ values. The results in Table 3 show that the $\log \beta$ value for $\mathrm{CuL}_{2}$ was larger, but that for $\mathrm{CuL}^{+}$was smaller. This is due to the steeper slope of the ECFC predicting that $\mathrm{CuL}_{2}$ forms at lower $\mathrm{pHs}$ that is really the case. The large standard deviation for the $\mathrm{CuL}^{+}$ species was due to the low value obtained for the $[\mathrm{L}]:[\mathrm{Cu}(\mathrm{II})]=207$ experiment. From Fig. S5 it can be seen that the $\delta$ values for this experiment were lower than that for the other two experiments, thus indicating that larger errors would be expected. Although the ECFC could be fitted when including only the $\mathrm{CuL}^{+}$and $\mathrm{CuL}_{2}$ species, points at the highest $\mathrm{pHs}$ could be better fitted by incorporating the $\mathrm{CuL}_{3}{ }^{-}$species (see Fig 4b) and the results are given in Table 3 . The $\mathrm{CuL}_{3}{ }^{-}$species is clearly an artefact from the overestimation of the $E_{1 / 2}$ values when the $E_{1 / 2}^{\mathrm{q}}(\mathrm{Cu})$ values were used.

It is only after both $E_{\mathrm{j}}$ and the non-reversible behaviour of the reduction of $\mathrm{Cu}$ (II) was accounted for that $\log \beta$ values comparable to those obtained in literature were obtained (see Table 2b).
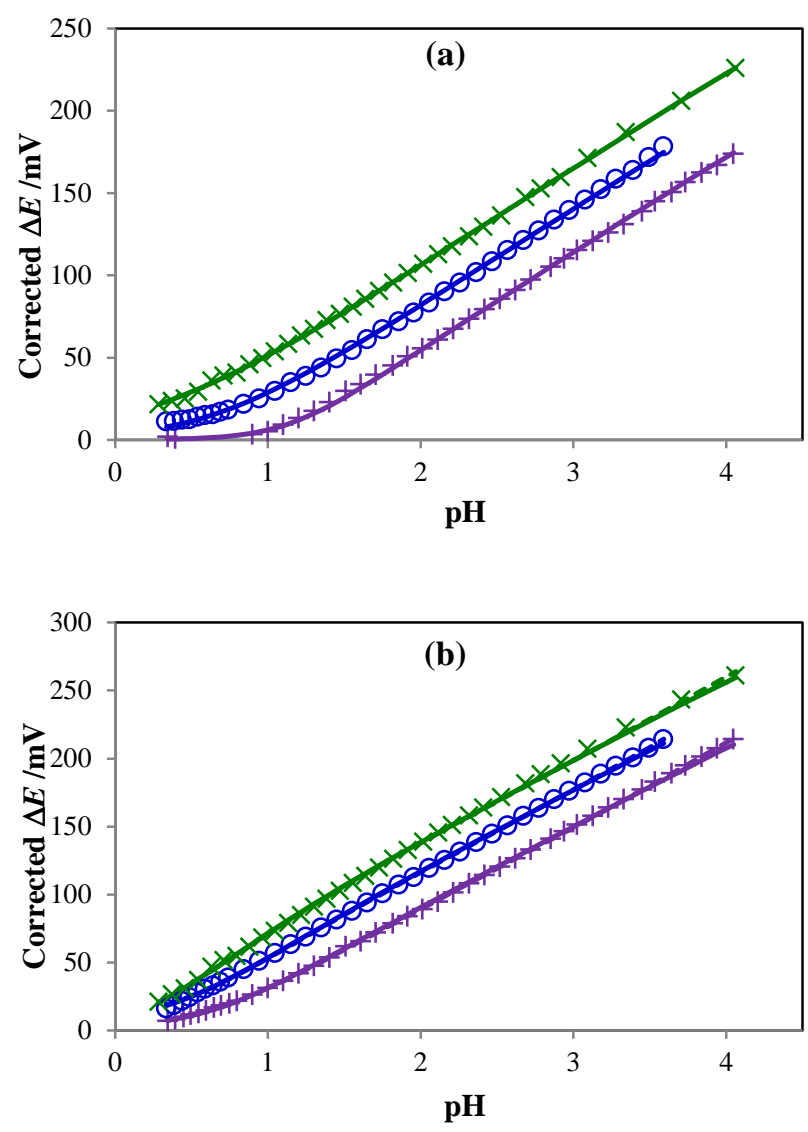

Fig. 4. Comparison of the ECFCs and corresponding CCFCs (-) calculated using the species model $\mathrm{CuL}^{+}$and $\mathrm{CuL}_{2}$ for $\mathrm{pH}$ titrations where [L]:[Cu(II)] is $32(+), 103(\bigcirc)$ and $207(\times)$ where (a) $E_{1 / 2}^{\mathrm{r}}$ values were used but no $E_{\mathrm{j}}$ correction was made and (b) $E_{\mathrm{j}}$ correction was made but $E_{1 / 2}^{\mathrm{q}}$ values were used. The $\mathrm{CuL}_{3}{ }^{-}$species could also be included in the model in (b) as indicated by the additional CFCCs (---).

\section{Conclusion}

This was an ideal metal-ligand system to test the protocols developed for working under very acidic conditions because $\mathrm{CuL}^{+}$only exists in solution below $\mathrm{pH}$ 2 for the concentration conditions used. Fig. $3 \mathrm{c}$ highlights that, for the conditions used, at $\mathrm{pH}-0.3$ about $10 \%$ of $\mathrm{Cu}$ (II) is complexed already and in a $1 \mathrm{M}$ acid solution, about $30 \%$ of $\mathrm{Cu}(\mathrm{II})$ is in the $\mathrm{CuL}^{+}$form and $\mathrm{CuL}_{2}$ has also started forming. An additional complication, however, was dealing with the quasi-reversible nature of $\mathrm{Cu}$ (II) reduction. The extent of irreversibility appears to be more strongly dependent on ionic strength than $\mathrm{pH}$ in nitrate solutions. The reduction of both uncomplexed $\mathrm{Cu}$ (II) and the $\mathrm{Cu}$ (II)-picolinic acid complexes was quasireversible at lower ionic strength (and higher $\mathrm{pH}$ in this case). In order to determine $E_{1 / 2}^{\mathrm{r}}$ from quasi-reversible DC waves (as required for stability constant evaluation) several approaches were considered, but only the 
rudimentary procedure by Cukrowski and Zhang [27] produced meaningful values. The $E_{1 / 2}(\mathrm{Cu})-\mathrm{pH}$ plot, predicted by subtracting $E_{\mathrm{j}}$ (determined using the Henderson equation) from $E(\mathrm{Cu})$, followed a similar trend to the $E_{1 / 2}^{\mathrm{r}}-\mathrm{pH}$ plots for uncomplexed $\mathrm{Cu}(\mathrm{II})$, thus giving confidence to the $E_{1 / 2}^{\mathrm{r}}$ values. In all three ligand titrations, the $\delta$ values from the $\mathrm{Cu}(\mathrm{II})$ reduction waves were all close to 0.9 indicating negligible deviation from a reversible reduction, hence the $E_{1 / 2}^{\mathrm{r}}$ values were thus close to the $E_{1 / 2}^{\mathrm{q}}$ values. The $E_{1 / 2}^{\mathrm{r}}$ values were used in all further calculations.

When working under very acidic conditions, the $\Delta E_{1 / 2}(\mathrm{M})-\mathrm{pH}$ model was first established and then used together with the $E_{1 / 2}(\mathrm{Tl})$ data collected when ligand was present in the test solution, to accurately predict the magnitude of $E_{\mathrm{j}}$ and the $E(\mathrm{Cu})$ value. The reversible $E_{1 / 2}\left(\mathrm{Cu}_{\text {comp }}\right)$ values could then be corrected for $E_{\mathrm{j}}$ and the ECFC calculated.

Several factors thus had to be taken into account to produce $\mathrm{Cu}(\mathrm{II})$ potential data, as initially obtained from the $\mathrm{pH}$ titration experiments, for use in the calculation of stability constants. These included (i) the determination of reversible potential values from quasi-reversible reduction waves, (ii) correcting for the large junction potentials $\left(E_{\mathrm{j}}\right.$ was about $30 \mathrm{mV}$ at $\mathrm{pH} 0.3$ ), (iii) the fact that $E_{\mathrm{j}}$ varies with $\mathrm{pH}$, (iv) the slightly larger shift in $E_{1 / 2}$ for $\mathrm{Tl}(\mathrm{I})$ compared to that for $\mathrm{Cu}$ (II) due to the changing ionic strength and (v) the indirect determination of $E(\mathrm{Cu})$ using $E(\mathrm{Tl})_{\text {ave }}$ and $\Delta E(\mathrm{M})_{\text {ave }}$ data. Additionally, it is critical that $\mathrm{pH}$ be determined as accurately as possible, thus methodologies developed to calibrate the glass electrode under acidic conditions were also employed. [2] Taking all these into consideration, the fact that the stability constants compared very well to the literature data shows the rigor of these protocols as well as robustness of polarography as a technique for determining these values.

It was demonstrated that when evaluating $\log \beta$ values using potential data (from $\mathrm{pH}$ titrations) that had not been corrected for $E_{\mathrm{j}}$, significantly smaller values were found as the both the $E(\mathrm{Cu})$ value and the reversible $E_{1 / 2}\left(\mathrm{Cu}_{\text {comp }}\right)$ values below $\mathrm{pH} \sim 2$ were lower than if $E_{\mathrm{j}}$ were accounted for. It was furthermore shown that when simply using the quasi-reversible $\mathrm{Cu}$ (II) reduction potentials, rather than those for a reversible electron transfer, the $\log \beta$ values for $\mathrm{CuL}_{2}$ were overestimated (leading to an underestimation of the $\log \beta$ values for $\left.\mathrm{CuL}^{+}\right)$and an additional artefact species $\left(\mathrm{CuL}_{3}{ }^{-}\right)$could even be included.

It was not necessary to compensate for $E_{\mathrm{j}}$ for the ligand titration data, provided $E(\mathrm{Cu})$ and $E\left(\mathrm{Cu}_{\text {comp }}\right)$ (as given in Eq. 2) are measured at the same pH. It may then be asked why it is necessary to do $\mathrm{pH}$ titration experiments which involve more correction factors. Since the type of metal-ligand species in solution depends on the $\mathrm{pH}, \mathrm{pH}$ titrations provide an overall notion of the speciation across a wide $\mathrm{pH}$ range. Once that is established, it is easier to assess at which $\mathrm{pH}$ to run a ligand titration and additional stability constant data can then be determined. Furthermore it is not always possible to do ligand titrations as the solubility of the ligand may be too low to make up ligand solutions, there may be a limited amount of ligand if only small quantities were synthesised, the metal ion may be hydrolysed at the $\mathrm{pH}$ at which a ligand titration is to be run (this means the $E(\mathrm{M})$ cannot be determined), it is problematic to detect protonated or hydrolysed species that are $\mathrm{pH}$ dependant and so on. It can therefore be concluded that polarography can be used to accurately determine stability constants for metalligand complexes formed below $\mathrm{pH} 2$ and this methodology can be applied to study unknown systems.

\section{Appendix: List of Selected Symbols}

\begin{tabular}{|c|c|}
\hline$E_{\mathrm{j}}$ & Diffusion junction potential. \\
\hline$E_{\text {appl }}$ & Applied potential to the working electrode. \\
\hline$E(\mathrm{M})$ & $\begin{array}{l}\text { Half-wave potential of the free or } \\
\text { uncomplexed metal ion. }\end{array}$ \\
\hline$E\left(\mathrm{M}_{\text {comp }}\right)$ & $\begin{array}{l}\text { Half-wave potential of the complexed metal } \\
\text { ion. }\end{array}$ \\
\hline$\Delta E$ & $\begin{array}{l}\text { The shift in potential due to complex } \\
\text { formation: } E(\mathrm{M})-E\left(\mathrm{M}_{\text {comp }}\right)\end{array}$ \\
\hline$E_{1 / 2}^{\mathrm{r}}$ & Reversible half-wave potential. \\
\hline$E_{1 / 2}^{\mathrm{q} / 2}$ & Quasi-reversible half-wave potential. \\
\hline$E_{1 / 2}^{\mathrm{i}}$ & Irreversible half-wave potential. \\
\hline$E_{1 / 2}(\mathrm{M})$ & Experimental half-wave potential. \\
\hline$\Delta E_{1 / 2}(\mathrm{M})$ & $\begin{array}{l}\text { The difference in the reversible experimental } \\
\text { half-wave potentials for } \mathrm{Cu}(\mathrm{II}) \text { and } \mathrm{Tl}(\mathrm{I}) \text { : } \\
E_{1 / 2}^{\mathrm{r}}(\mathrm{Cu})-E_{1 / 2}(\mathrm{Tl})\end{array}$ \\
\hline$E(\mathrm{M})_{\text {ave }}$ & $\begin{array}{l}\text { The average value of the experimental half- } \\
\text { wave potentials for the free metal ion above } \\
\text { pH } 2(=E(\mathrm{M}))\end{array}$ \\
\hline$\Delta_{\mu} E_{1 / 2}(\mathrm{M})_{0.5-0.25}$ & $\begin{array}{l}\text { The change in the reversible half-wave } \\
\text { potential for a metal ion caused only by the } \\
\text { change in ionic strength (from } 0.5 \text { to } 0.25 \\
\text { M). }\end{array}$ \\
\hline$I(\mathrm{M})$ & $\begin{array}{l}\text { Diffusion-limited current for the free or } \\
\text { uncomplexed metal ion. }\end{array}$ \\
\hline$I\left(\mathrm{M}_{\text {comp }}\right)$ & $\begin{array}{l}\text { Diffusion-limited current complexed metal } \\
\text { ion. }\end{array}$ \\
\hline [L] & Free ligand concentration. \\
\hline$[\mathrm{M}]$ & Free metal ion concentration. \\
\hline$\left[\mathrm{M}_{\mathrm{T}}\right]$ & Total metal ion concentration. \\
\hline
\end{tabular}

\section{Acknowledgements}

This work is based on the research supported by the National Research Foundation (NRF) and the University 
of the Witwatersrand. Any opinion, finding and conclusion or recommendation expressed in this material is that of the authors and the NRF does not accept responsibility in this regard.

\section{References}

[1] A.E Martel, R.D. Hancock, Metal complexes in Aqueous Solutions, Plenum Press, New York, 1996

[2] C. Billing, I. Cukrowski, S. Afr. J. Chem. 2009, 62, 168

[3] K. Suzuki, M. Yasuda, K. Yamasaki, J. Phys. Chem. 1957, 61,229

[4] R.C. Mercier, M. Bonnet, M.R Paris, Bull. Soc. Chim. Fr. 1965, 2926

[5] C. Petitifaux, J. Barbier, J. Faucherre, Bull. Soc. Chim. Fr. 1970, 3441

[6] R. Aruga, J. Inorg. Nucl. Chem. 1979, 41, 845

[7] G. Anderegg, Helv. Chim. Acta 1960, 43, 414

[8] F. Holmes, W.R.C. Crimmin, J. Chem. Soc. 1955, 1175

[9] C. Petitifaux, R. Fournaise, Bull. Soc. Chim. Fr. 1972, 914

[10] S.C. Chang, J.K.H. Ma, J.T. Wang, N.C. Li, J. Coord. Chem. 1972, 2, 31

[11] I. Cukrowski, J.M. Zhang, A. van Aswegen, Helv. Chim Acta 2004, 87, 2135

[12] C.M.M. Machado, I. Cukrowski, H.M.V.M. Soares, Helv. Chim. Acta 2003, 86, 3288

[13] C. Billing, I. Cukrowski, B. Jordan, Electroanalysis 2013, 25,2221

[14] A.E. Martell, R.M. Smith, R.J. Motekaitis, NIST Standard Reference Database 46 Version 8.0, NIST Critically Selected Stability Constants of Metal Complexes, USA, 2004
[15] C. Billing, D.C. Levendis, V.L. Vieira, S. Afr. J. Chem. 2011, 64, 38

[16] J.J. Lingane, Chem. Rev. 1941, 29, 1

[17] I. Cukrowski, Anal. Chim. Acta 1996, 336, 23

[18] C.M.A. Brett, A.M.O. Brett, Electrochemistry Principles, Methods and Applications, Oxford University Press Inc., UK, 1993

[19] I. Cukrowski, P. Franklyn, 3D-CFC software, Windows Version 1.2, unpublished

[20] I. Cukrowski, H.M. Marques, T.S. Mkwizu, P.P. Magampa, C. Serge, Anal. Chim. Acta 2007, 590, 203

[21] I.M. Kolthoff, Y. Okinaka, J. Am. Chem. Soc. 1959, 81, 2296

[22] F.M Hawkridge Jr., H.H. Bauer, Anal. Chem. 1972, 44, 364

[23] J.L. Anderson, I. Shain, Anal. Chem. 1976, 48, 1274

[24] J.L. Anderson, I. Shain, Anal. Chem. 1978, 50, 163

[25] J. Koryta, Electrochim. Acta 1962, 6, 67

[26] I. Ružić, A. Barić, M. Branica, J. Electroanal. Chem. 1971, 29, 411

[27] I. Cukrowski, J.M. Zhang, Electroanalysis 2004, 16, 612

[28] H. Matsuda, Y. Ayabe, Bull. Chem. Soc. Japan 1955, 28 , 422

[29] H. Matsuda, Y. Ayabe, Bull. Chem. Soc. Japan 1956, 29, 132

[30] H. Matsuda, Y. Ayabe, Z. Elektrochem. 1959, 64, 1164

[31] T.S.P. Mkwizu, A Polarographic and Potentiometric Study of Metal-Ligand Equilibria: Instrumentation and Investigations of Systems with Non-Reversible Electrode Reactions, MSc Dissertation, University of the Witwatersrand, 2006 
Supplementary Information 


\section{Examples of experimental curves}

A set of polarograms for both a $\mathrm{pH}$ and a ligand titration experiment is shown in Fig. S1a and S1b, respectively, to illustrate the change in the polarograms with changing solution conditions. In Fig. S1a it is clearly seen that as the $\mathrm{pH}$ was increased, the reduction wave for the $\mathrm{Cu}$ (II) species shifted to more negative potentials and the steepness of the wave decreased as reduction became less reversible. The reduction potential of $\mathrm{Tl}(\mathrm{I})$ shifted in a positive direction only below $\mathrm{pH} \sim 2$ due to the changing $E_{\mathrm{j}}$. The decrease in the current with increasing $\mathrm{pH}$ was mainly due to dilution on addition of the hydroxide solution. In Fig. S1b the reduction potential of $\mathrm{Tl}(\mathrm{I})$ was unchanged because the $\mathrm{pH}$ was kept constant throughout the titration and hence $E_{\mathrm{j}}$ was constant. The reduction wave for the $\mathrm{Cu}$ (II) species shifted to more negative potentials with increasing ligand concentration as expected. The decrease in current was far less in this case as very small volumes of the $0.5001 \mathrm{M}$ picolinic acid solution were added.
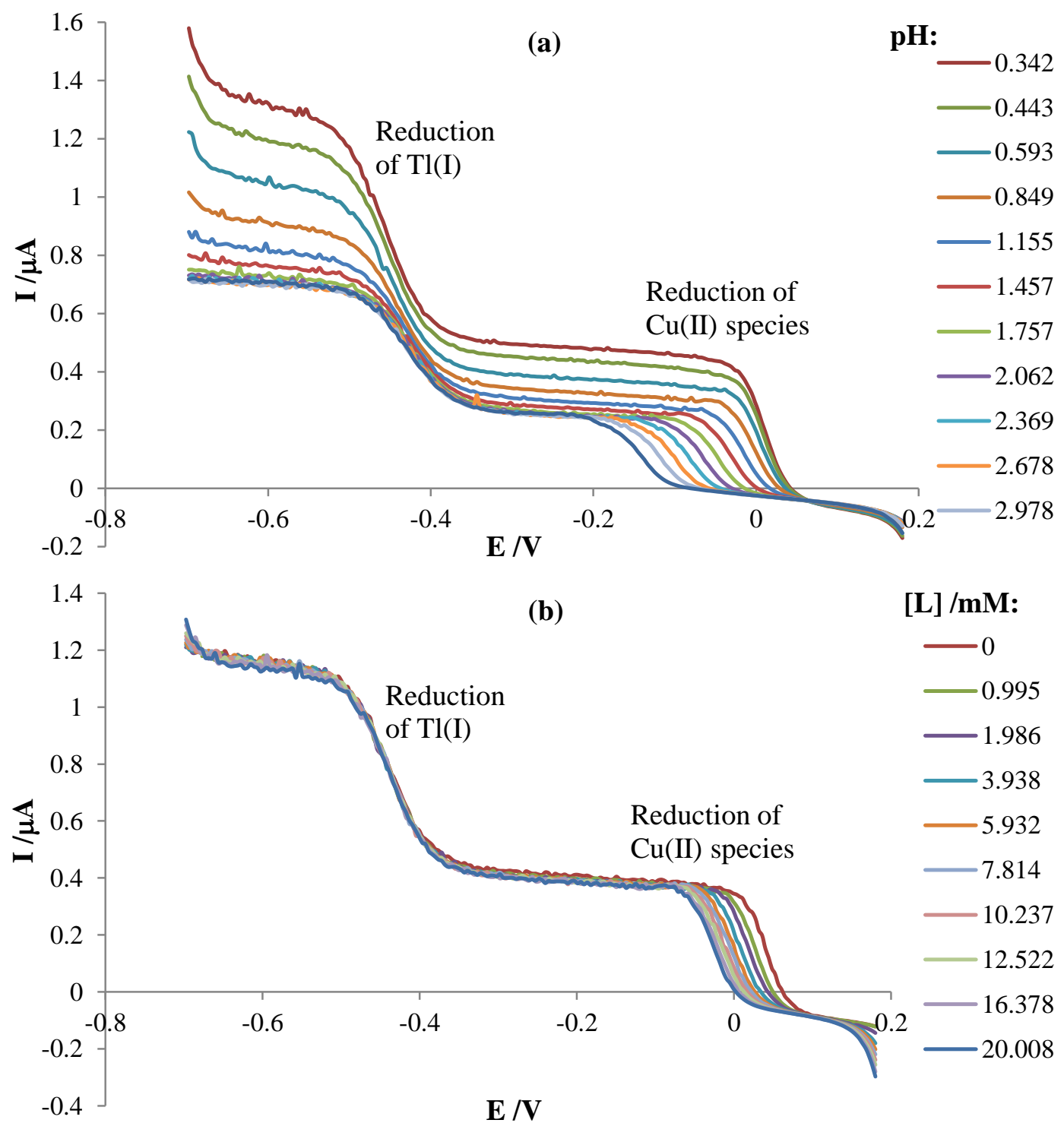

Fig. S1. Selected polarograms for (a) a $\mathrm{pH}$ titration where $[\mathrm{L}]:[\mathrm{M}]=103$ and (b) a ligand titration at $\mathrm{pH} 0.90$. 


\section{Variation in electrochemical reversibility of $\mathrm{Cu}(\mathrm{II})$ reduction}

Fig. S2 gives examples of the change in the value of $\delta$ (which indicates the extent of reversibility) for the reduction of $\mathrm{Cu}$ (II) species in the absence and presence of picolinic acid. In the absence of ligand, a similar trend is noted between the change in ionic strength and the decrease in the extent of reversibility.

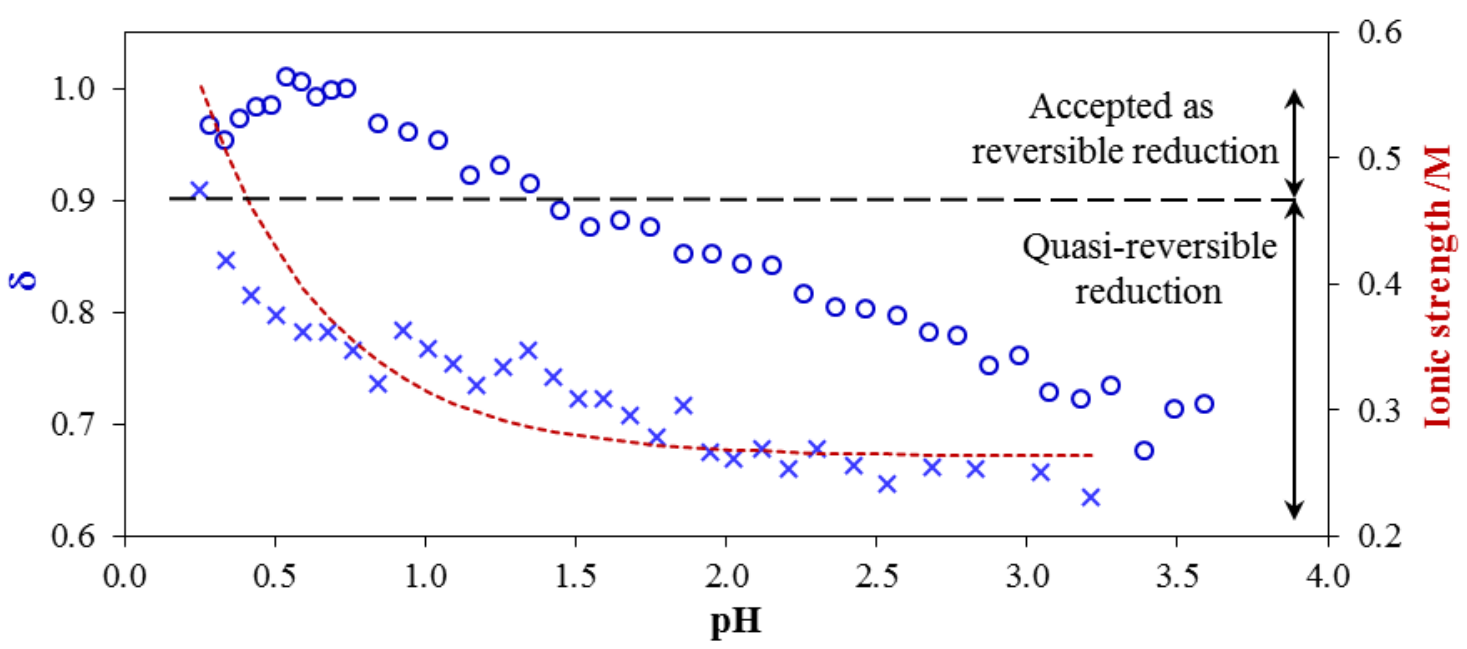

Fig. S2. The value of $\delta$ illustrates the change in the electron transfer rate for the reduction of $\mathrm{Cu}(\mathrm{II})$ in a nitrate background in the absence $(\times)$ and presence $(\mathrm{O})$ of picolinic acid (where $[\mathrm{Cu}(\mathrm{II})]:[\mathrm{L}]=103$ ). The variation in ionic strength of the solution is also indicated (---). 


\section{An example of logarithmic analysis of electrochemical reversibility}

Due to the reduction of $\mathrm{Cu}(\mathrm{II})$ being quasi-reversible, various procedures were attempted to determine the reversible $E_{1 / 2}$ values as required for determining stability constants. Fig. S3 shows the attempted use of $\log$ analysis where asymptotes drawn from data at the foot of the wave, are exptrapolated to the $E$-axis where the intercept values correspond to the reversible $E_{1 / 2}$ values. [21,22] Here the difficulty in deciding where to draw the asymptotes is highlighted and the significant difference in the reversible $E_{1 / 2}$ values are shown.

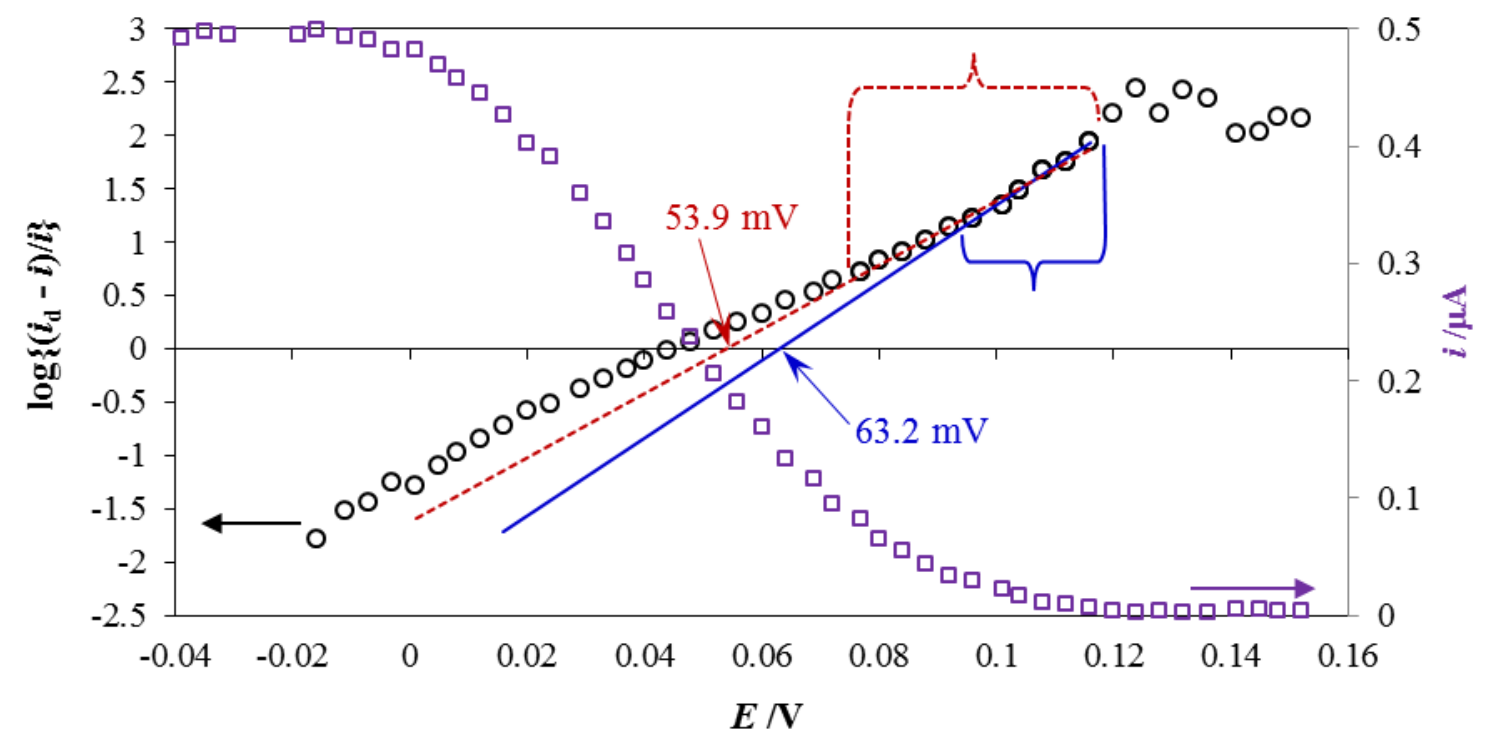

Fig. S3. Log analysis showing two possible asymptotes that could be extrapolated to determine $E_{1 / 2}^{\mathrm{r}}$. The brackets indicate the data points used to calculate each of these. The DC wave with subtracted background current is also displayed ( $\square$ ). 


\section{Protocol used to monitor $E_{1 / 2}$ of $\mathrm{Cu}(\mathrm{II})$ relative to $\mathrm{Tl}(\mathrm{I})$.}

Fig. S4 shows the difference in the $E_{1 / 2}^{\mathrm{r}}$ values between $\mathrm{Cu}(\mathrm{II})$ and $\mathrm{Tl}(\mathrm{I})\left(\right.$ i.e. $\Delta E_{1 / 2}(\mathrm{M})=E_{1 / 2}^{\mathrm{r}}(\mathrm{Cu})-$ $\left.E_{1 / 2}(\mathrm{Tl})\right)$ determined at each $\mathrm{pH}$ for five data sets when using data from $\mathrm{pH}$ titrations in the absence of ligand. The average $\Delta E_{1 / 2}(\mathrm{M})-\mathrm{pH}$ relationship was modelled by a fifth order polynomial below $\mathrm{pH}$ 2.7. This difference was used to account for slight differences in shifts in $E_{1 / 2}$ for $\mathrm{Cu}$ (II) and $\mathrm{Tl}$ (I) due to the decreasing ionic strength (from $0.5 \mathrm{M}$ to about $0.25 \mathrm{M}$ ) during the titration. Above $\mathrm{pH} 2.7$ the value of $\Delta E_{1 / 2}(\mathrm{M})$ was taken as constant.

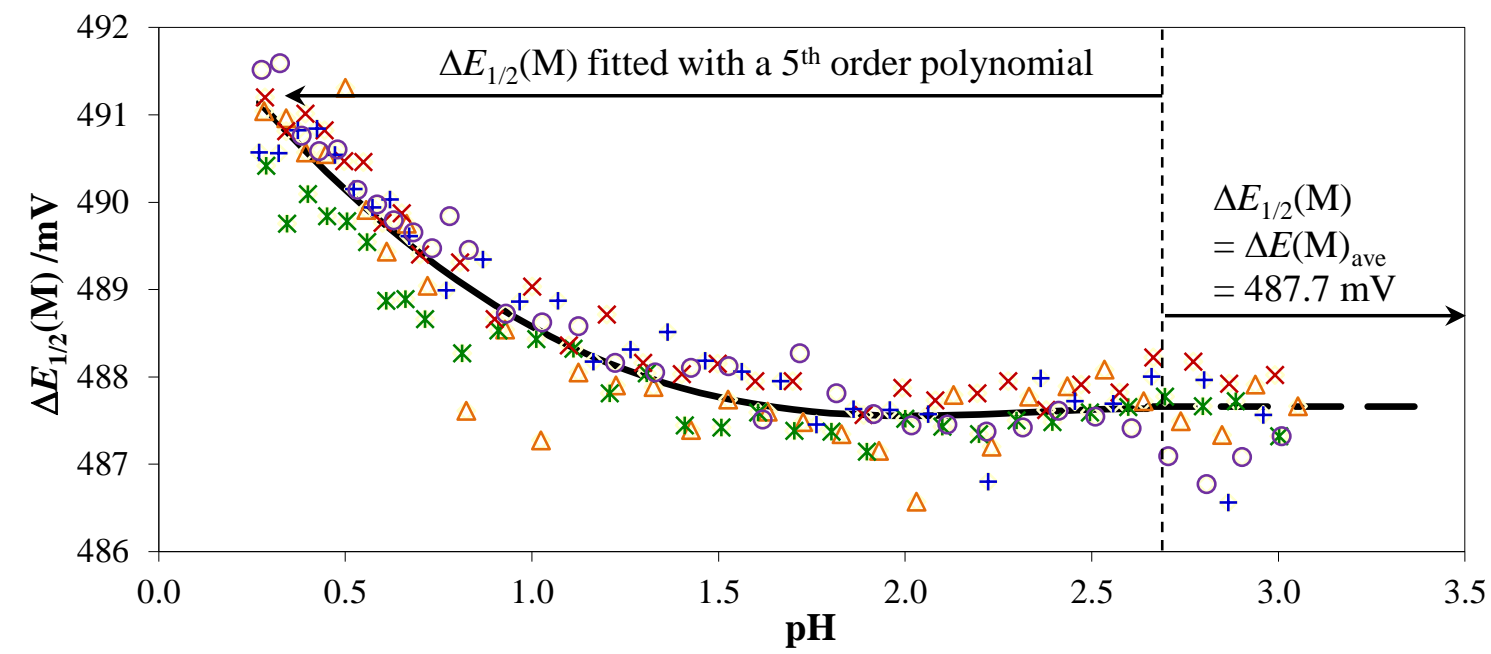

Fig. S4. Model of the reversible $E_{1 / 2}(\mathrm{Cu})-E_{1 / 2}(\mathrm{Tl})$ values as a function of $\mathrm{pH}$ for five data sets. Above $\mathrm{pH} 2.7$, $\Delta E_{1 / 2}(\mathrm{M})=\Delta E(\mathrm{M})_{\text {ave }}$. 
Fig. S5 shows the values of $\delta$ obtained for the three $\mathrm{pH}$ titration experiments, and particularly highlights the lower values obtained for the $[\mathrm{L}]:[\mathrm{Cu}(\mathrm{II})]=207$ experiment.

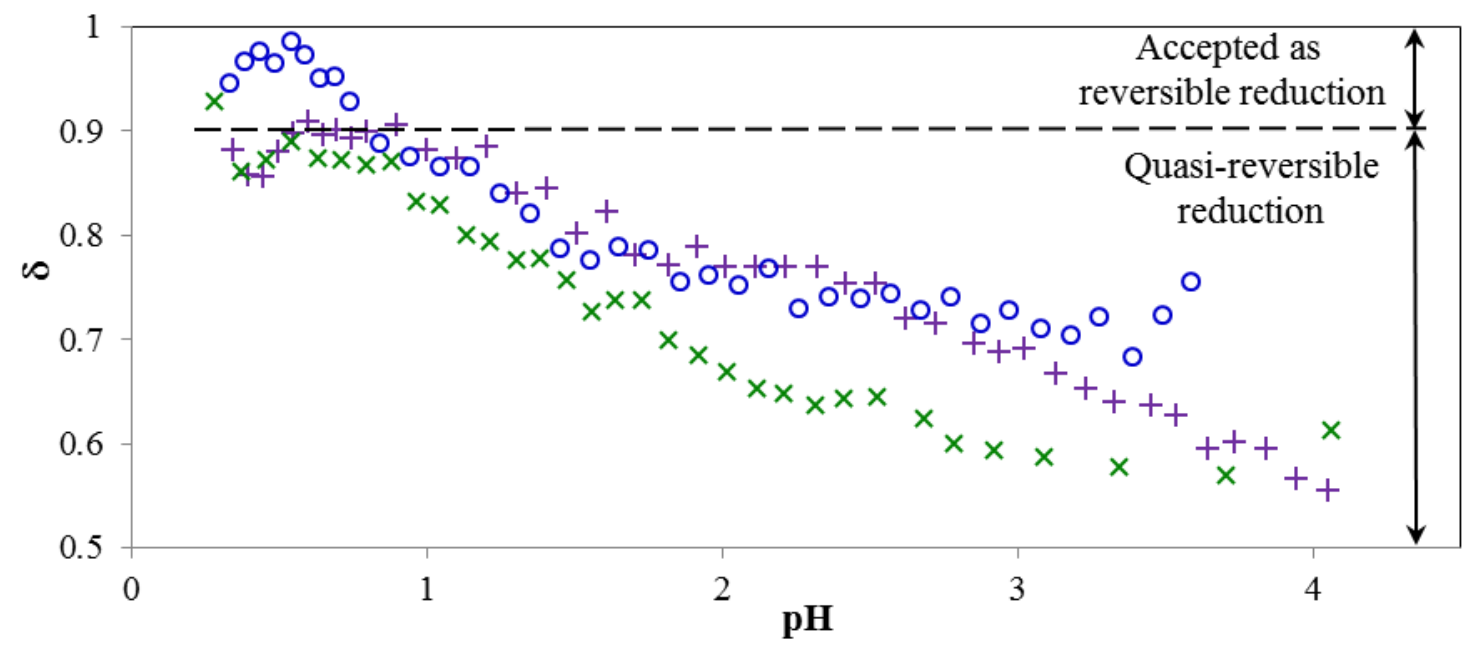

Fig. S5. Comparison of the $\delta$ values for $\mathrm{pH}$ titrations where [L]: $[\mathrm{Cu}(\mathrm{II})]$ is $32(+), 103(\mathrm{O})$ and $207(\times)$. 


\section{Error analysis in the computed formation constants}

An expanded table of results obtained for the separate $\mathrm{pH}$ titration experiments is given in Table S1. The average values are quoted in Table 3 . The standard deviation of fitting is calculated by $\sqrt{ }(\mathrm{SSE} /(n-$ $p)$ ), where SSE is the sum of squares of error, $n$ is the number of experimental points used and $p$ is the number of parameters refined.

Table S1. $\log \beta$ values calculated for $\mathrm{CuL}^{+}$and $\mathrm{CuL}_{2}$ when using (a) $E_{1 / 2}^{\mathrm{r}}$ values but no $E_{\mathrm{j}}$ correction; (b) $E_{1 / 2}^{\mathrm{q}}$ values with $E_{\mathrm{j}}$ correction; (c) $E_{1 / 2}^{\mathrm{q}}$ values with $E_{\mathrm{j}}$ correction, but including the $\mathrm{CuL}_{3}{ }^{-}$species in the model; (d) $E_{1 / 2}^{\mathrm{r}}$ values and $E_{\mathrm{j}}$ correction.

\begin{tabular}{|c|c|c|c|c|}
\hline$[\mathrm{L}]:[\mathrm{Cu}(\mathrm{II})]$ & 32 & 103 & 207 & Average \\
\hline \multicolumn{5}{|l|}{ (a) } \\
\hline $\log \beta_{1}$ & $6.51 \pm 0.08$ & $7.40 \pm 0.02$ & $7.87 \pm 0.01$ & $7.26 \pm 0.69$ \\
\hline $\log \beta_{2}$ & $13.881 \pm 0.007$ & $13.706 \pm 0.008$ & $13.942 \pm 0.009$ & $13.84 \pm 0.12$ \\
\hline S.D. of fitting & 2.85 & 2.58 & 0.83 & \\
\hline \multicolumn{5}{|l|}{ (b) } \\
\hline $\log \beta_{1}$ & $7.81 \pm 0.02$ & $7.85 \pm 0.02$ & $6.71 \pm 0.38$ & $7.46 \pm 0.65$ \\
\hline $\log \beta_{2}$ & $15.094 \pm 0.007$ & $14.994 \pm 0.007$ & $15.079 \pm 0.007$ & $15.04 \pm 0.08$ \\
\hline S.D. of fitting & 1.93 & 1.40 & 3.54 & \\
\hline \multicolumn{5}{|l|}{ (c) } \\
\hline $\log \beta_{1}$ & $7.85 \pm 0.02$ & $7.88 \pm 0.02$ & $6.98 \pm 0.21$ & $7.57 \pm 0.51$ \\
\hline $\log \beta_{2}$ & $15.050 \pm 0.009$ & $14.917 \pm 0.009$ & $15.064 \pm 0.008$ & $15.01 \pm 0.08$ \\
\hline $\log \beta_{3}$ & $18.84 \pm 0.06$ & $18.34 \pm 0.10$ & $17.86 \pm 0.10$ & $18.35 \pm 0.49$ \\
\hline S.D. of fitting & 0.38 & 0.77 & 2.86 & \\
\hline \multicolumn{5}{|l|}{ (d) } \\
\hline $\log \beta_{1}$ & $7.77 \pm 0.02$ & $7.88 \pm 0.02$ & $7.61 \pm 0.05$ & $7.75 \pm 0.14$ \\
\hline $\log \beta_{2}$ & $14.895 \pm 0.007$ & $14.826 \pm 0.007$ & $14.915 \pm 0.007$ & $14.88 \pm 0.05$ \\
\hline S.D. of fitting & 0.54 & 1.84 & 1.94 & \\
\hline
\end{tabular}

